\title{
Pollen morphology and infrageneric classification of selected Callicarpa species (Lamiaceae) from the Philippines and Borneo
}

\author{
JENNIFER S. DANILA ${ }^{1, \bullet}$, GRECEBIO JONATHAN D. ALEJANDRO ${ }^{1,2}$ \\ ${ }^{1}$ The Graduate School, University of Santo Tomas. España Blvd., 1015 Manila, Philippines \\ vemail: jennifer.danila.gs@ust.edu.ph \\ ${ }^{2}$ College of Science and Research Centre for the Natural and Applied Sciences, University of Santo Tomas. España Blvd., 1015 Manila, Philippines
}

Manuscript received: 30 October 2020. Revision accepted: 24 November 2020.

\begin{abstract}
Danila JS, Alejandro GJD. 2020. Pollen morphology and infrageneric classification of selected Callicarpa species (Lamiaceae) from the Philippines and Borneo. Biodiversitas 21: 5736-5746. We used pollen grains of ten species representing the controversial genera Geunsia Blume and Callicarpa L. from the key centers of Malesia - Philippines, and Borneo including other countries in Asia. Herbarium specimens and collected samples from the field were examined using Scanning Electron Microscopy (SEM) in search of new characters to establish conclusive evidence that might contribute to the study of the relationship between Geunsia and Callicarpa. Based on SEM observations, both the investigated pollen grains of Geunsia and Callicarpa are mostly small to medium, spheroidal or circular, prolate to oblate, isopolar, and tricolpate. Moreover, the exine surface is mostly coarsely reticulated with a thin perforated colpus edge and sunken finely granulated colpus membrane. However, exine ornamentation shows possible separation of Geunsia and Callicarpa due to various morphological results observed. Several types of exine ornamentation were found in species of the section Callicarpa, i.e., C. erioclona, C. arborea, C. macrophylla, and C. candicans which attributes in the projected separation of these species while four species in the section Geunsia are united as a group having coarsely reticulate exine. Surprisingly, C. arborea samples give additional support to the hypothesis that rugulate exine sculpture might be its plesiomorphic character due to evolutionary evidence of other exine types of this species. On the other hand, pollen size and shape class of the sections of Geunsia and Callicarpa were both observed with similar features having an average pollen size equivalent to medium and a prolate shape supporting the concept of previous studies to nest Geunsia within Callicarpa. This reveals that pollen morphology is useful in the study of infrageneric classification within these groups. However, further morphological studies involving larger number of specimens are needed especially in the study of exine to prove its consistency as diagnostic character in the study of phylogenetic relationship.
\end{abstract}

Keywords: Exine, Geunsia, palynology, phylogeny, SEM

\section{INTRODUCTION}

Callicarpa $\mathrm{L}$. is among the largest genera of the family Lamiaceae with approximately 170 shrub species $(\mathrm{Li}$ and Olmstead 2017). The genus is characterized by hairs branched/stellate (simple); inflorescences axillary; flowers polysymmetric, 4(-5) merous; anthers porose; stigma peltate or capitate; and fruit a drupe (Linnaeus, 1753). These plants are made up of an incredibly diverse group of species in terms of their ecology, morphology, and geographical distribution. Among those species that illustrate comparable distributional patterns of Callicarpa were found in key centers of Malesia - the Philippines and the island Borneo having 27 and 23 species, respectively (Pelser et al. 2011; Bramley 2013).

Since Linnaeus (1753) established Callicarpa, the struggle of taxonomic revision continued due to inconsistency in its infrageneric classification. After several group modifications (Murray 1774; Lamark 1783, 1791; Gaertner 1791; Loureiro 1783; Raeuschel 1797), Callicarpa has been assigned to a more confident family Verbenaceae (Brown, 1810). In support of Verbenaceae, Briquet (1895) further used calyx characters to form two distinct groups either Tubulosae (tubular) or Cyathimorphae (campanulate) calyx. Furthermore, Chang
(1951) used stamen characters to distinguish either as Eucallicarpa with small, ovate, longitudinally dehiscent anthers or Verticirima with larger oblong anthers. Later, more infrageneric classifications were established such as Fang's (1982) division of species based on hair types classified as two subgenera: Subgen. Peiantha is characterized by simple cymes and curved hair while Subgen. Callicarpa with various hair types. Despite all these proposed morphological classifications, Callicarpa has been formally transferred and settled in the family Lamiaceae based on floral morphological characters and DNA sequences (Thorne 1992; Cantino et al. 1992). However, the circumscription of the genus Callicarpa remains uncertain due to overlapping characters, e.g., stamen and hair types (Chang 1951; Fang 1982). Also, Abraham-Oanes (2002) and Ma et al. (2015) attempted to compare these characters vs pollen morphology but failed to include species from wider samples in the Malesian region.

Several taxonomists like Raj (1983), Wei (2003), and Perveen and Qaiser (2007) attempted to classify Callicarpa species through morphology. But the data appears inadequate when only a few species were described. Liu (1985) improved the number of collections, but most samples were examined under a light microscope. In the 
study conducted by Ma et al. (2015), pollen grains of Callicarpa were studied to determine the taxonomic position of Callicarpa but the samples were limited only to Callicarpa sect. Eucallicarpa and Verticirima and involves no samples of Philippine Callicarpa.

Later, several taxonomists investigated that Callicarpa shows affinities with genus Geunsia, distinguished in Blume's (1823) Catalogus based on its first known sample, G. farinosa Blume. Investigations includes Briquet (1897) testing floral parts either teramerous and pentamerous contradict the relationship of Callicarpa and Geunsia while Lam (1919), Ridley (1923), Moldenke (1981) considered Geunsia and Callicarpa as related to each other along with Schauer (1847), Lam and Bakhuizen van den Brink (1921), van Steenis (1967), Burtt (1969) who treated the two genera as exactly like the other. Currently, the longestablished Geunsia has been regarded as synonyms to genus Callicarpa (Lam and Bakhuizen van den Brink 1921; Govaert et al. 2007). Due to morphological questionings from leaf arrangement and petiole to the ovary (Lam 1919), section Geunsia has been tested its relationship to section Eucallicarpa and Verticirima (Bramley 2009) suggesting that its relationship between groups were not resolved due to paraphyly of species in the section Callicarpa. Lam (1919) and Chang (1951) proposed morphological characters used to distinguished sections Callicarpa and Geunsia which turn into weak evidence because characters e.g., characters of leaf arrangement and anther appear in numerous sections.

Palynological characters became a trend in classifying species worldwide. Cantino and Sanders (1986), Abu-Asab and Cantino (1993), Harley (2004), and Celenk et al. (2008) upholds the study of pollen grain as a useful tool in the classification of the members of the family Lamiaceae. However, previous palynological works of Callicarpa by Abraham-Oanes (2002) and Ma et al. (2015) constitute only collections from Malaysia and China, respectively, while neither species from the Philippines nor other parts of Borneo were used in palynology. Thus, immediate palynological reinvestigation to cover species from these two lands is necessary as Ma et al. (2015) pointed out the necessity of the further detailed study of non-Chinese species for a better understanding of Callicarpa taxonomic character.

The objective of this paper is to provide a detailed description of the pollen morphology of Callicarpa from the Philippines and Borneo using scanning electron microscopy (SEM). Likewise, it will identify the relevant diagnostic character and be able to use this palynological information in the infrageneric classification of Callicarpa and its relationship to Geunsia.

\section{MATERIALS AND METHODS}

\section{Study area}

Field studies was conducted in Mt. Bulusan, Sorsogon Province and Samar Island Natural Park (SINP), Eastern Samar Province, Philippines to collect pollen grains from fresh inflorescence of Callicarpa species (Figure 1).

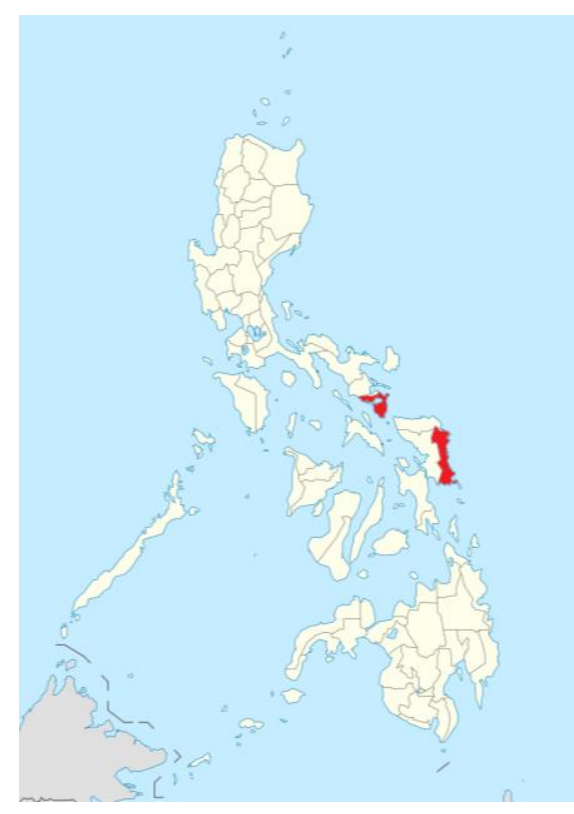

$\mathbf{A}$

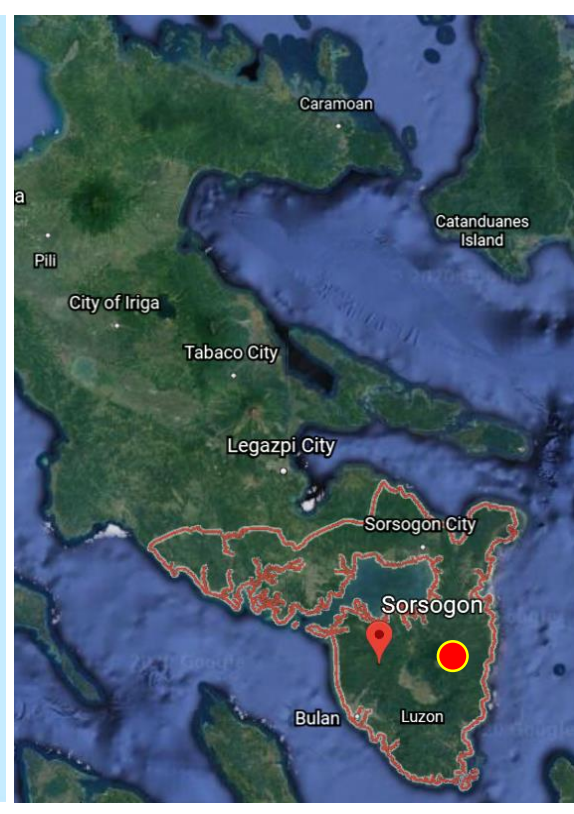

$\mathbf{B}$

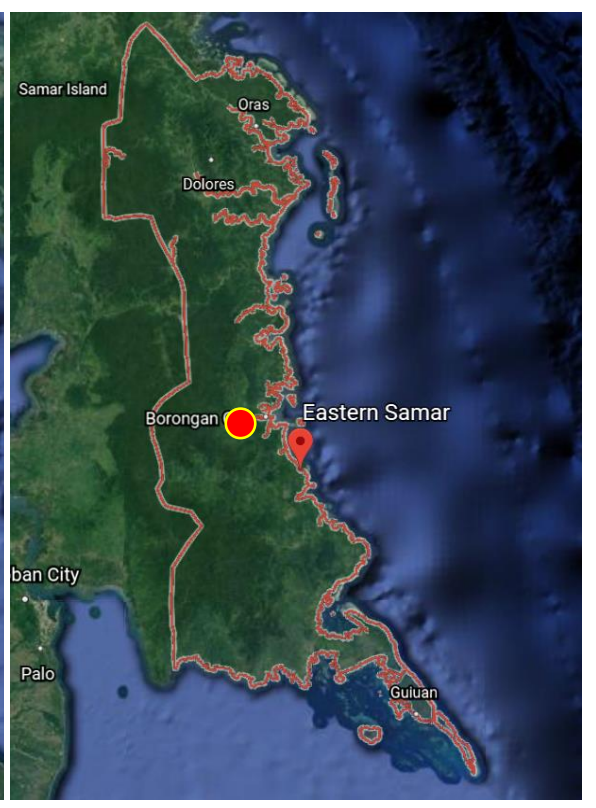

C

Figure 1. Map of the Philippines (right) showing: A. Mt. Bulusan in Sorsogon Province, B. Samar Island Natural Park (SINP), Samar Province where field collection took place (red dots). 


\section{Plant materials}

Pollen grains were mostly taken from the dried specimen from herbarium in Singapore (SIN) while some were collected in a form of fresh inflorescence. Pollen of 10 of 15 taxa was used in scanning electron microscopy. Three to five individuals per species from herbarium were used to represent species of Philippines and Borneo including some samples from India (C. arborea Roxb. and C. macrophylla Vahl.) and China (C. candicans (Burm.f.) Hochr.) for which these samples are included in Bramley (2009) species in Borneo and essential for comparison.

\section{Procedures}

Pollen grains of both herbarium and fresh samples were acetolyzed following combined procedures of Erdtman (1952), Hou (1969), Nilsson (2000), and Hesse et al. (2018). The acetolyzed pollen samples were dehydrated in an ethanol series and mounted in aluminum stubs with double-sided adhesive tape. Pollen grains were described using Hitachi TM-3000 Tabletop Microscope operated at $15 \mathrm{KV}$ at the UST Research Center for the Natural and Applied Sciences (RCNAS). The polar axis and the equatorial axis were measured. The characterization of the pollen of each species like the shape, outline in polar view, and size range was determined by calculating the equatorial diameter $(\mathrm{P} / \mathrm{E})$ ratios. Most of the measurements were obtained using the Image $\mathrm{J}$ software. Moreover, pollen ornamentation, polarity, amb, aperture type, colpus edge, colpus membrane, exine type, and pollen units were determined. Pollen terminology is based on Punt et al. (2007) descriptions.

\section{RESULTS AND DISCUSSION}

Materials examined for pollen morphological studies of Callicarpa and Geunsia species are provided in Table 1, while pollen size and shape measurements are presented in Table 2. Representative pollen grains are illustrated in Figures 2-9.

\section{General description of pollen of Callicarpa}

Pollen grains of Callicarpa is monad, spheroidal while some are circular. Its apertures are typically tricolpate and rarely inaperturate. The sizes of the grain range from small $(10-25 \mu \mathrm{m})$ to medium size $(26-50 \mu \mathrm{m})$. The shape classes are mostly subprolate $(1.14-1.33 \mu \mathrm{m})$ to prolate $(1.33-2.00$ $\mu \mathrm{m})$ where areas in some species appear oblate spheroidal $(0.88-1.00 \mu \mathrm{m})$ and subspheroidal $(0.75-1.33 \mu \mathrm{m})$ sometimes with irregular infoldings. The number of apertures is mostly 3 but there are recorded species without apertures. The polarity of pollen is mostly isopolar. The outline (amb) demonstrated several types from circular, polygonal to elliptical contour of the pollen either in polar or equatorial view. The colpus has a thin and perforated edge while either sunken, finely or coarsely granulated but rarely raised, coarsely granulated colpus membrane. The exine exhibits reticulated ornamentation either rugosely reticulate, rugulate, micro reticulate, or coarsely reticulate forming muri with lumina.
Table 1. Materials examined for pollen morphological studies of Callicarpa and Geunsia species

\begin{tabular}{lll}
\hline Species & Localities & Acc. no. \\
\hline Callicarpa species & & \\
C. arborea Roxb. & India & N/A \\
C. arborea Roxb. & Java, Indonesia & 507180 \\
C. arborea Roxb. & Samar, Philippines & JDS001 \\
C. candicans (Burm.f.) Hochr. Kwangsi, China & 451 \\
C. erioclona Schauer & Sorsogon, Philippines & SOR006 \\
C. erioclona Schauer & Bataan, Philippines & 4142 \\
C. macrophylla Vahl & India & 28 \\
C. pedunculata R. Br. & Aurora, Philippines & JDA001 \\
C. pedunculata R. Br. & Albay, Philippines & 18195
\end{tabular}

\section{Geunsia species}

C. anomala (Ridl.) B.L. Burtt Sarawak, Malaysia 0035867

$\begin{array}{lll}C \text {. pentandra Roxb. } & \text { Selangor, Malaysia } 101082\end{array}$

C. scandens (Moldenke) Govaerts Sabah, Malaysia 144078

$\begin{array}{lll}\text { G. cumingiana Schauer } & \text { Panay, Philippines } & 31179\end{array}$

G. cumingiana Schauer $\quad$ Albay, Philippines 18424

G. farinosa Roxb. ex C.B Clarke Sabah, Malaysia 0152106

\section{Species-level pollen descriptions for Callicarpa/Geunsia Callicarpa species}

\section{C. arborea Roxb. (Figure 2 A-J; India)}

Pollen unit: monad, size (pollen unit): small to mediumsized $(10-25 \mu \mathrm{m}$ to $26-59 \mu \mathrm{m})$, pollen class: tricolpate, polarity: heteropolar, shape: suboblate, oblate spheroidal to oblate and prolate spheroidal, subprolate to prolate, outline in polar view: circular to spheroidal, infoldings: aperture(s) sunken, aperture number: three, aperture type: colpus, aperture condition: colpate, aperture peculiarities: aperture membrane ornamented colpus edge: thin perforate colpus membrane: sunken, finely granulate ornamentation: regulate to microreticulate.

\section{C. arborea Roxb. (Figure 2, K; Java, Indonesia)}

Pollen unit: monad, size (pollen unit): medium-sized (26-59 $\mu \mathrm{m})$, pollen class: tricolpate, polarity: heteropolar, shape: subprolate spheroidal, outline in polar view: prolate infoldings: aperture(s) sunken, aperture number: three, aperture type: colpus, aperture condition: colpate, aperture peculiarities: aperture membrane ornamented colpus edge: thin perforate colpus membrane: sunken, finely granulate ornamentation: coarsely reticulate.

\section{C. arborea Roxb. (Figure 2, L-N; Samar Philippines)}

Pollen unit: monad, size (pollen unit): medium-sized (26-59 $\mu \mathrm{m})$, pollen class: inaperturate, polarity: -, shape: subprolate, outline in polar view: spheroidal, infoldings: not infolded, aperture number: none, aperture type: no aperture, aperture condition: inaperturate, aperture peculiarities: - colpus edge: thin perforate colpus membrane: sunken, finely granulate ornamentation: rugosely reticulate. 
C. candicans (Burm. F.) Hochr. (Figure 3, A-C; Kwangsi, China)

Pollen unit: monad, size (pollen unit): small to mediumsized $(10-25$ to $26-59 \mu \mathrm{m})$, pollen class: tricolpate, polarity: isopolar, shape: prolate, outline in polar view: spheroidal, infoldings: aperture(s) sunken, aperture number: three, aperture type: colpus, aperture condition: colpate, aperture peculiarities: aperture membrane ornamented colpus edge: thin perforate colpus membrane: sunken, finely granulate ornamentation: micro reticulate.

\section{C. erioclona Shauer (Figure 4, A-B; Sorsogon, Philippines)}

Pollen unit: monad, size (pollen unit): small-sized (10-25 $\mu \mathrm{m})$, pollen class: inaperturate, polarity: -, shape: oblate, outline in polar view: spheroidal, infoldings: not infolded, aperture number: none, aperture type: no aperture, aperture condition: inaperturate, aperture peculiarities: colpus edge: thin perforate colpus membrane: sunken, finely granulate ornamentation: rugosely reticulate.

\section{C. erioclona Schauer (Figure 4, C-G; Bataan, Philippines)}

Pollen unit: monad, size (pollen unit): medium-sized (26-59 $\mu \mathrm{m})$, pollen class: tricolpate, polarity: isopolar, shape: oblate, outline in polar view: spheroidal, infoldings: aperture(s) sunken, aperture number: three, aperture type: colpus, aperture condition: colpate, aperture peculiarities: aperture membrane ornamented colpus edge: thin perforate colpus membrane: sunken, finely granulate ornamentation: coarsely reticulate.

\section{C. macrophylla Vahl. (Figure 5, A-H, Figure 6 A-C; India)}

Pollen unit: monad, size (pollen unit): small to mediumsized $(10-25$ to $26-59 \mu \mathrm{m})$, pollen class: tricolpate, polarity: isopolar, shape: prolate, outline in polar view: spheroidal, infoldings: aperture(s) sunken, aperture number: three, aperture type: colpus, aperture condition: colpate, aperture peculiarities: aperture membrane ornamented colpus edge: thin perforate colpus membrane: sunken, finely granulate ornamentation: rugosely reticulate to rugulate

C. pedunculata R. Br. (Figure 7, A-B; Aurora, Philippines) Pollen unit: monad, size (pollen unit): medium-sized (26-59 $\mu \mathrm{m})$, pollen class: colpate, polarity: heteropolar, shape: subprolate to prolate, outline in polar view: spheroidal, infoldings: aperture(s) sunken, aperture number: three armed furrows like aperture, aperture type: colpus, aperture condition: colpate, aperture peculiarities: aperture membrane ornamented colpus edge: thin perforate colpus membrane: sunken, finely granulate ornamentation: coarsely reticulate.

C. pedunculata R.Br. (Figure 7, C-H; Albay, Philippines)

Pollen unit: monad, size (pollen unit): small-sized (10-25 $\mu \mathrm{m})$, pollen class: tricolpate, polarity: isopolar to heteropolar, shape: prolate, outline in polar view: spheroidal, infoldings: aperture(s) sunken, aperture number: three, aperture type: colpus, aperture condition: colpate, aperture peculiarities: aperture membrane ornamented colpus edge: thin perforate colpus membrane: sunken, finely granulate ornamentation: microreticulate.

\section{Geunsia species}

C. anomala (Ridl.) B.L. Burtt (Figure 8, A-B; Sarawak, Malaysia)

Pollen unit: monad, size (pollen unit): medium-sized (26-59 $\mu \mathrm{m})$, pollen class: tricolpate, polarity: heteropolar, shape: prolate, outline in polar view: spheroidal, infoldings: aperture(s) sunken, aperture number: three, aperture type: colpus, aperture condition: colpate, aperture peculiarities: aperture membrane ornamented colpus edge: thin perforate colpus membrane: sunken, finely granulate ornamentation: coarsely reticulate.

\section{C. pentandra Roxb. (Figure 8, C-D, Figure 9 A; Selangor, Malaysia)}

Pollen unit: monad, size (pollen unit): medium-sized (26-59 $\mu \mathrm{m})$, pollen class: colpate, polarity: isopolar, shape: prolate spheroidal to oblate spheroidal, outline in polar view: circular, infoldings: aperture(s) sunken, aperture number: three, aperture type: colpus, aperture condition: colpate, aperture peculiarities: aperture membrane ornamented colpus edge: thin perforate colpus membrane: sunken, raised granulate ornamentation: coarsely reticulate.

\section{C. scandens (Moldenke) Govaerts (Figure 9 B, F; Sabah,} Malaysia)

Pollen unit: monad, size (pollen unit): small-sized (10-25 $\mu \mathrm{m})$, pollen class: colpate, polarity: heteropolar, shape: prolate, outline in polar view: elliptic, infoldings: aperture(s) sunken, aperture number: three, aperture type: colpus, aperture condition: colpate, aperture peculiarities: aperture colpus edge: thin perforate colpus membrane: sunken, finely granulate membrane ornamented ornamentation: coarsely reticulate.

\section{G. cumingiana Schauer (Figure 9, C-E; Panay, Philippines)}

Pollen unit: monad, size (pollen unit): small-sized (10-25 $\mu \mathrm{m})$, pollen class: tricolpate, polarity: heteropolar, shape: prolate to oblate spheroidal, outline in polar view: spheroidal, infoldings: aperture(s) sunken, aperture number: three, aperture type: colpus, aperture condition: colpate, aperture peculiarities: aperture membrane ornamented colpus edge: thin perforate colpus membrane: sunken, finely granulate ornamentation: rugulate.

\section{G. cumingiana Schauer (Figure 9, F-G; Albay, Philippines)}

Pollen unit: monad, size (pollen unit): medium-sized (26-59 $\mu \mathrm{m})$, pollen class: tricolpate, polarity: isopolar, shape: prolate spheroidal, outline in polar view: circular, infoldings: aperture(s) sunken, aperture number: three, aperture type: colpus, aperture condition: colpate, aperture peculiarities: aperture membrane ornamented colpus edge: thin perforate colpus membrane: sunken, finely granulate ornamentation: coarsely reticulate. 
G. farinosa Roxb. ex C.B Clarke (Figure 9, H-M; Sabah, Malaysia)

Pollen unit: monad, size (pollen unit): medium-sized $(26-59 \mu \mathrm{m})$, pollen class: sulcate to tricolpate, polarity: isopolar, shape: oblate spheroidal to prolate spheroidal, outline in polar view: spheroidal, infoldings: aperture(s) sunken, aperture number: three, aperture type: colpus, aperture condition: colpate, aperture peculiarities: aperture membrane ornamented colpus edge: thin perforate colpus membrane: sunken, finely granulate ornamentation: coarsely reticulate.

The investigated pollen grains of Callicarpa species were studied for the first time except for $C$. arborea, $C$. candicans, C. macrophylla, and C. pedunculata which were previously described by $\mathrm{Ma}$ et al. (2015) in the collection of Callicarpa in China. However, the authors of this study used non-Chinese samples of the abovementioned species except $C$. candicans which was originated in Kwangsi, China. The samples used in this study are mostly collected from Singapore herbarium (SIN) covering a wider range of samples from the Philippines and Borneo including few collections from India and China. Based on SEM observations, most of the investigated pollen of the sections Geunsia and Callicarpa were medium in size but few small-sized pollens were also observed. Palynological measurements including polar axis $(\mathrm{P})$, equatorial axis $(\mathrm{E})$, and $\mathrm{P} / \mathrm{E}$ ratio were tabulated to identify the pollen size of each sample based on Erdtman (1971) and Halbritter (2018) pollen size category. Pollen size range (Table 2) in the sections Callicarpa (P: 24.00-41.88 $\mu \mathrm{m}$ E: $21.34-33.67 \mu \mathrm{m}$ P/E: $0.87-1.29 \mu \mathrm{m})$

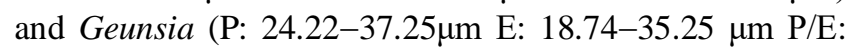
$0.97-1.36 \mu \mathrm{m}$ ) showed little or no significant differences in all quantitative characters. The smallest pollen grain of the section Callicarpa was recorded in C. macrophylla (26.04 $\times 21.34 \mu \mathrm{m})$ while the largest in C. candicans $(33.20 \times$ $26.20 \mu \mathrm{m})$. On the other hand, section Geunsia showed $C$. scandens $(25.42 \times 18.74 \mu \mathrm{m})$ and G. farinosa $(37.25 \times$ $35.25 \mu \mathrm{m})$ produced the smallest and largest pollen grain respectively. Since Callicarpa and Geunsia appear almost equal in the pollen size category thus, pollen size does not support the supposition that Callicarpa species is distinct from Geunsia species.

The shape class of the pollen grain was obtained by computing the ratio of the polar (P) and equatorial (E) axis (Erdtman 1952). The study shows that most of the pollen grains are prolate with polar and equatorial axis ratios $(\mathrm{P} / \mathrm{E})$ equals to 1.33-2.00 $\mu \mathrm{m}$ shown in species of $C$. pedunculata (Figure 7.A-H), C. scandens (Figure 9.B), G. farinosa (Figure 9.H-M), C. anomala (Figure 8.A-B), $C$. macrophylla (Figure 5.A-H, Figure 6.A-C), and $C$. candicans (Figure 3.A-C). Other shape class includes oblate found in C. erioclona (Figure 4.A-G) with P/E: 0.88-1.00 $\mu \mathrm{m}$ while remaining species like $C$. pentandra (Figure 8.C-D, Figure 9.A), C.arborea (Figure 2.A-N) and G. cumingiana (Figure 9.C-G) have shape variations from oblate (P/E: $0.50-0.75 \mu \mathrm{m})$, suboblate (P/E: $0.75-0.88$ $\mu \mathrm{m})$, oblate spheroidal (P/E: $0.88-1.00 \mu \mathrm{m})$, prolate spheroidal (P/E: 1.00-1.14 $\mu \mathrm{m}$ ), subprolate (P/E: 1.14-1.33 $\mu \mathrm{m})$, and prolate (P/E: $1.33-2.00 \mu \mathrm{m})$. According to Sebsebe and Harley (1992) and Ma et al. (2015), differences in the variations of size are due to acetolysis treatment when the colpal membranes are easily destroyed from hydration and fixation. To reduce destruction in the colpal membranes of highly inconsistent species, $C$. pentandra, C. arborea, and G. cumingiana, trial and error procedure of Hou (1969) was undertaken in this study to control the acetolysis procedure to reduce the chance of getting too dark images that affect features for observation.

Table 2. Pollen grain size and shape measurements of Callicarpa and Geunsia species

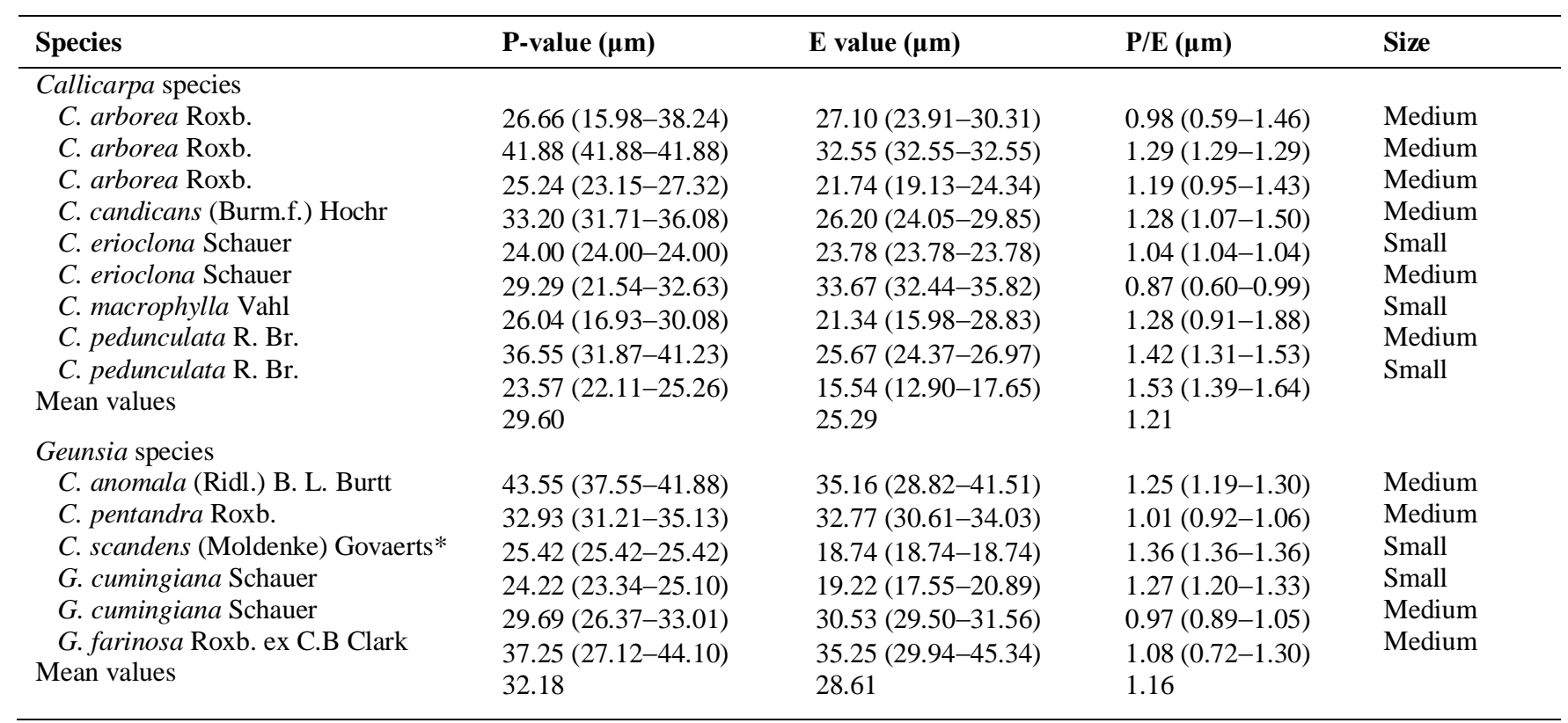



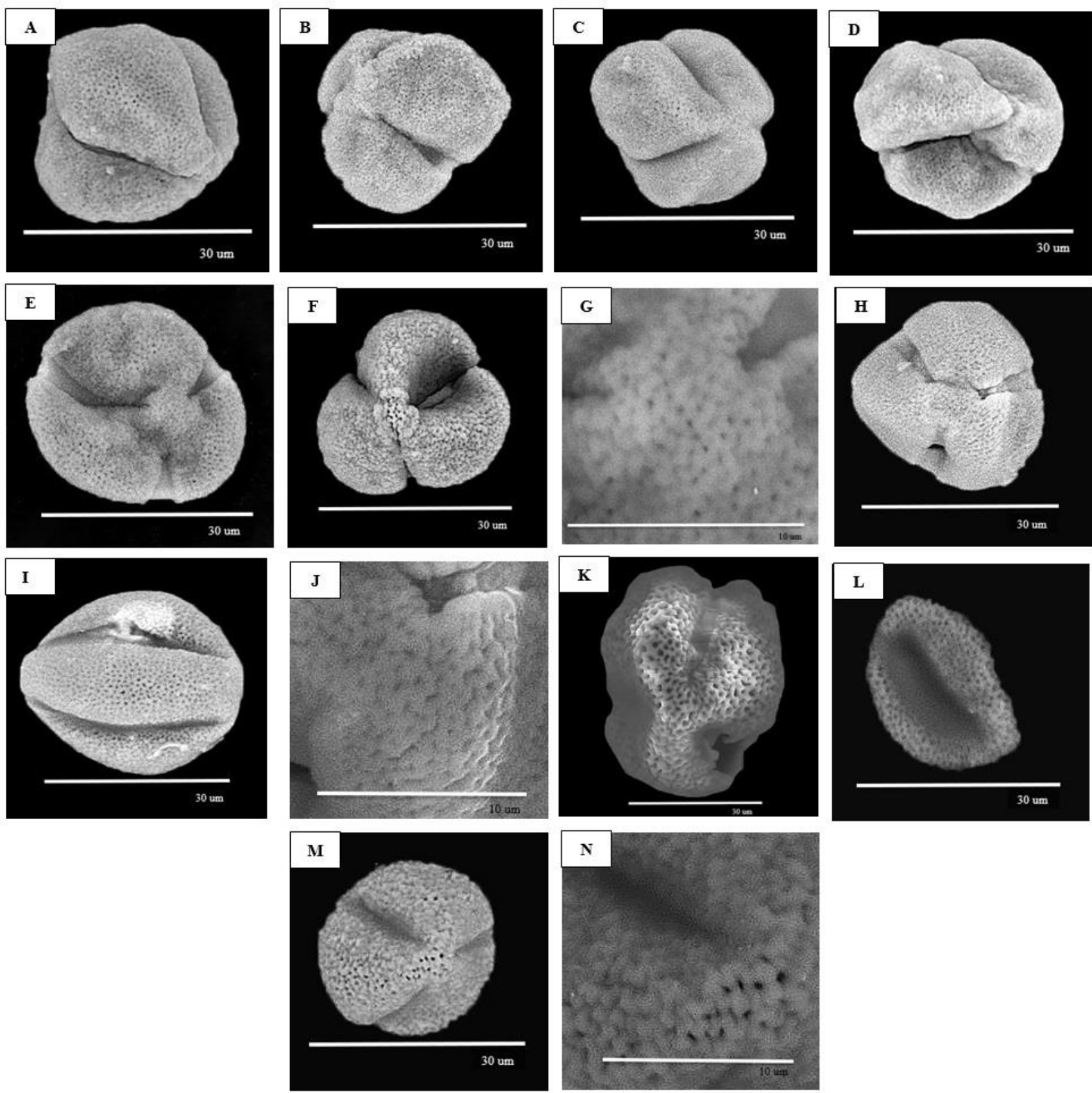

Figure 2. SEM micrographs of pollen grains of Callicarpa. A-J: C. arborea (India): (a-d) equatorial view (e-f) polar view(g,j) exine surface (h) polar view (i) equatorial view K: C. arborea (Java, Indonesia) equatorial view. L-N: C. arborea (Samar, Philippines) (l) equatorial view (m) polar view (n) exine surface
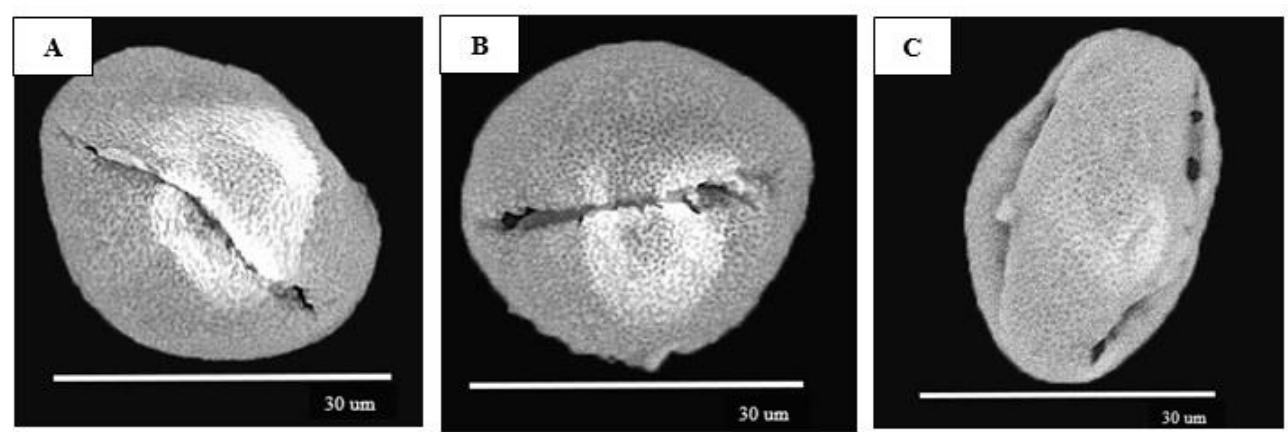

Figure 3. SEM micrographs of pollen grains of Callicarpa. surface A-C: C. candicans, equatorial view 

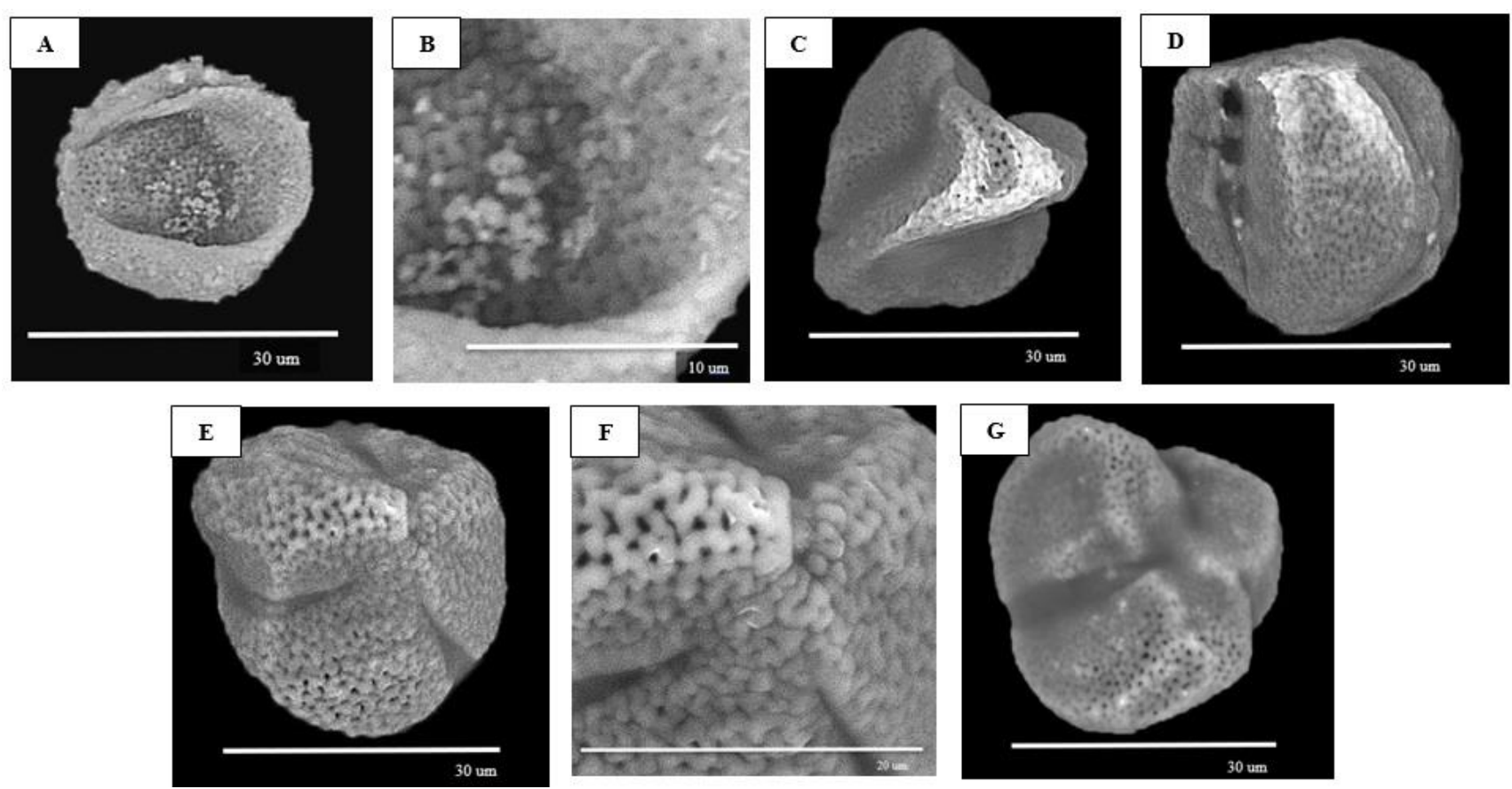

Figure 4. SEM micrographs of pollen grains of Callicarpa. A-B: C. erioclona (Sorsogon, Philippines) (b) exine surface G: $C$. erioclona (Bataan, Philippines) (c,e,g) polar view (d) equatorial view (f) exine surface
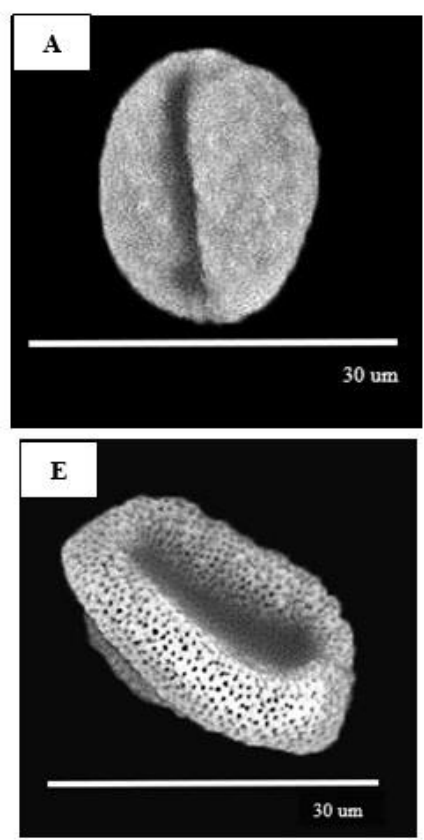
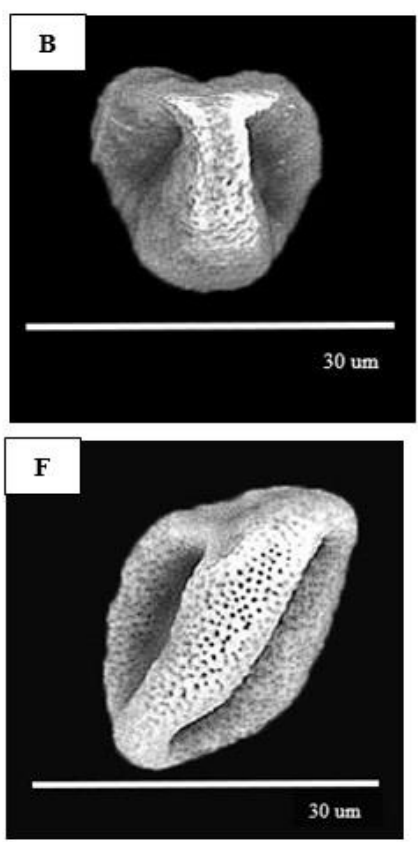
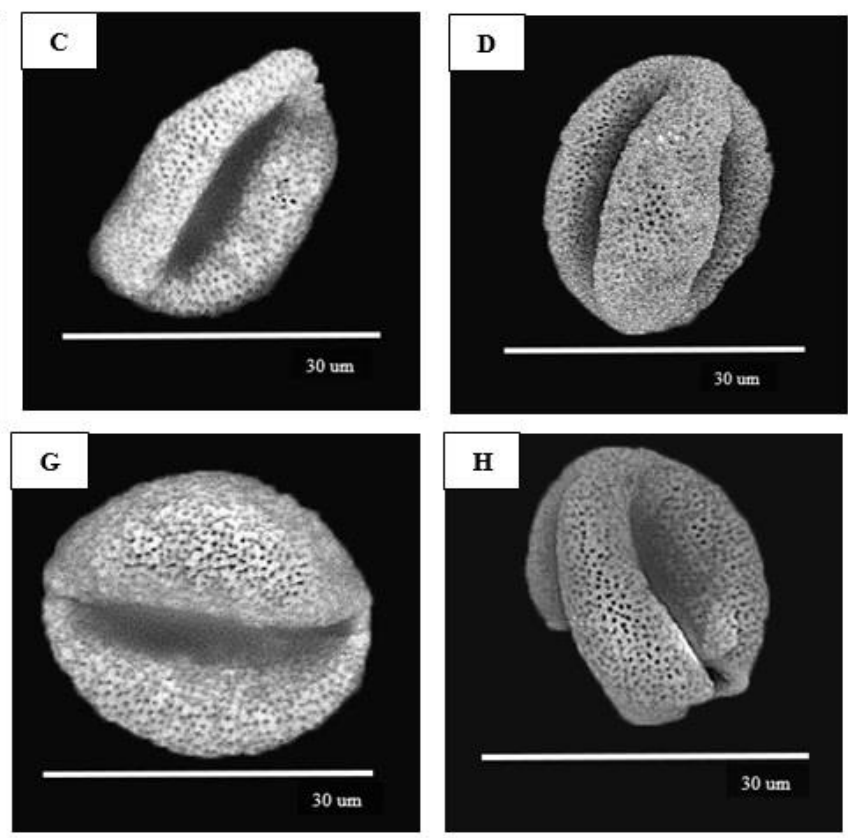

Figure 5. SEM micrographs of pollen grains of Callicarpa. A-H: C. macrophylla. $(\mathrm{a}-\mathrm{h})$ equatorial view 

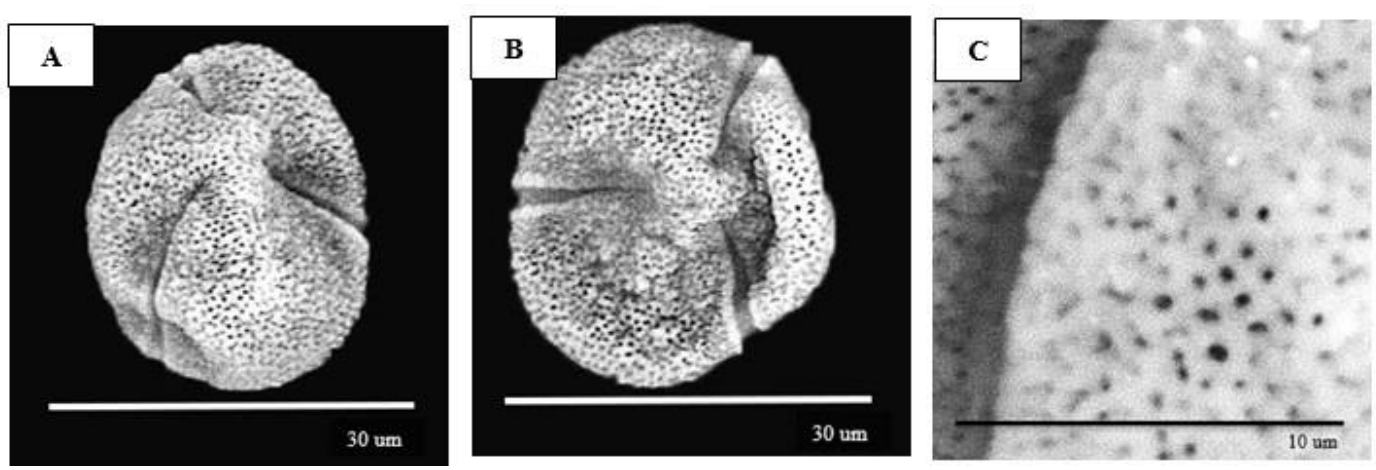

Figure 6. SEM micrographs of pollen grains of Callicarpa. A-C: C. macrophylla (a-b) polar view (c) exine surface.
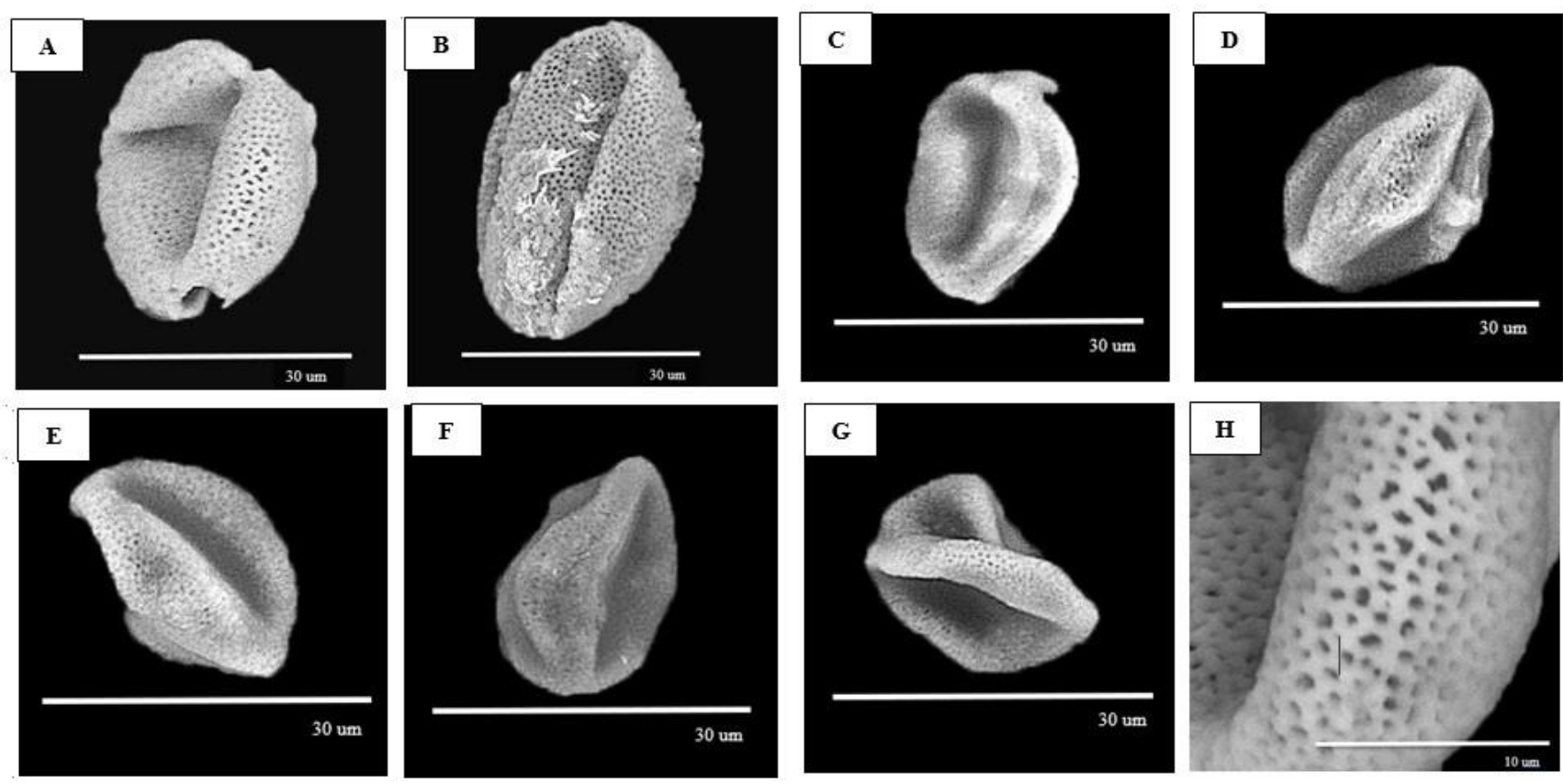

Figure 7. SEM micrographs of pollen grains of Callicarpa. A-B: C. pedunculata (Aurora, Philippines) (a-b) equatorial view C- H: $C$. pedunculata (Albay, Philippines) (c-g) equatorial view (h) exine surface
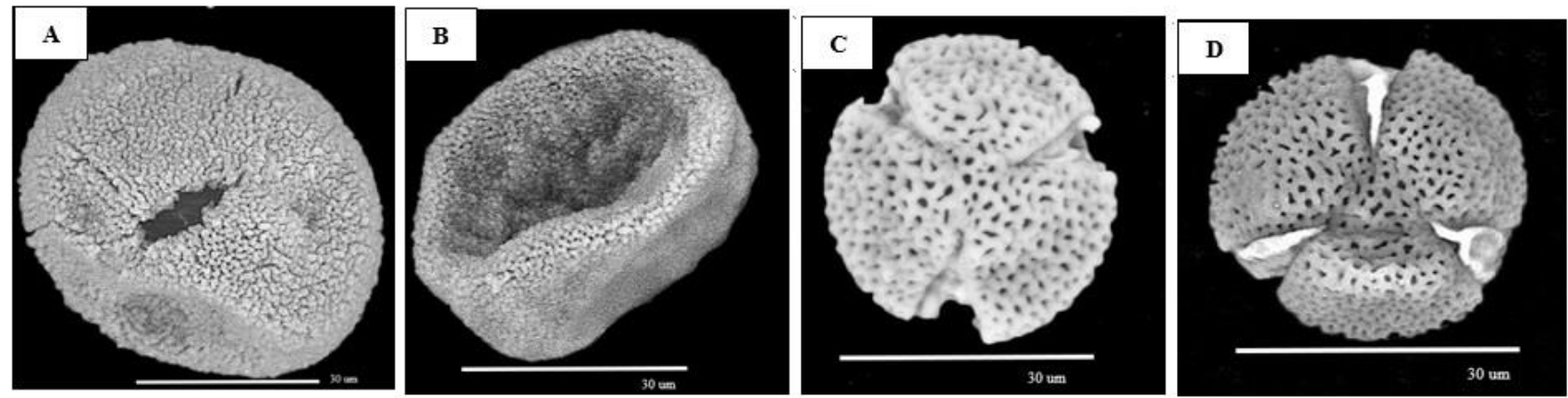

Figure 8. SEM micrographs of pollen grains of Geunsia. A-B: C. anomala: (a) exine surface (b) monad showing inaperturate face. C-D: $C$. pentandra, polar view 

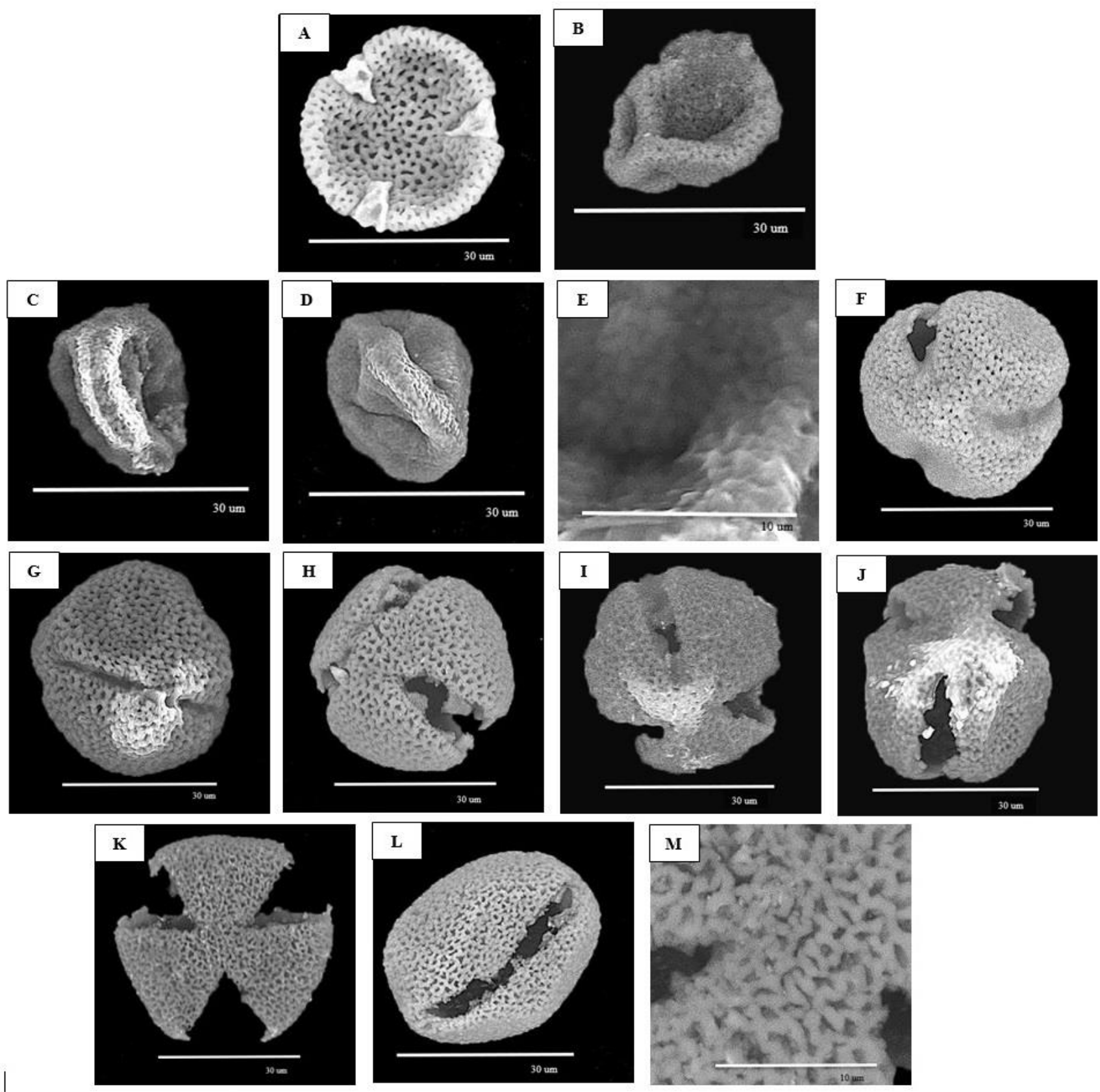

Figure 9. SEM micrographs of pollen grains of Geunsia. A: C. pentandra, polar view B: C. scandens, equatorial view C-E: G.cumingiana (Panay, Philippines) (c-d) equatorial view (e) exine surface F-G: G. cumingiana (Albay, Philippines) (f) polar view (g) equatorial view H-M: G. farinosa.(h-k) polar view (l) equatorial view (m) exine surface

Species belong to Geunsia group include C. scandens, $C$. pentandra, and $C$. anomala, all have prolate in shape except $G$. farinosa from Borneo which has prolate spheroidal to oblate spheroidal and G. cumingiana from the Philippines has prolate to oblate spheroidal. Some inconsistent species like $C$. scandens achieved additional support from this study when recent phylogenetic study (Bramley 2009) of Callicarpa surprisingly included C.scandens in the section Geunsia where initially most of its flower and fruit morphology was more of Callicarpa. On the other hand, members of Callicarpa which include C. arborea, C. erioclona, C. macrophylla, and C. candicans also show various shapes from prolate, prolate spheroidal to oblate. Both sections of Geunsia and Callicarpa were demonstrated with samples having prolate in shape which supports the suggestion of Bramley (2009) to nest Geunsia within Callicarpa. However, the authors suggest extending wider samples to increase the reliability of shape class as a diagnostic character since other samples show variations in shape.

The exine of Callicarpa shows considerable variation in texture which can be of strong diagnostic value. Coarsely reticulate is the most common type of tectum surface ornamentation among the observed species, it occurs in 7 
species (C. pedunculata, G. farinosa, C. pentandra, C. anomala, C. scandens, G. cumingiana, and C. erioclona). Other types of surface ornamentation include microreticulate $(C$. candicans), and rugulate $(C$. arborea and $C$. macrophylla). The exine sculpture of two members of section Geunsia, $C$. pentandra and $C$. scandens examined in the present study share interesting similarities with samples originally described as $G$. cumingiana and $G$. farinosa. This shows evidence that exine ornamentation provides evidence to support that $C$. pentandra, $C$. scandens, G. farinosa, and G. cumingiana were united to support the synonymy of Geunsia and Callicarpa. On the other hand, pollen grains of $C$. arborea of the section Callicarpa are characterized by their rugulate exine sculptures, although coarsely reticulate, rugosely reticulate, and microreticulate exine sculptures were also observed in a few $C$. arborea species. This may give additional support to the hypothesis that rugulate exine sculptures might be plesiomorphic character state of $C$. arborea and the coarsely reticulate, rugosely reticulate and microreticulate exine sculptures might have evolved independently more than once as it may show evolutionary evidence in this species.

Various types of exine ornamentation were also observed in other members of the section Callicarpa, i.e., C. erioclona, C. macrophylla, and C. candicans which attributes to the projected separation of these species. Exine sculptures of the taxa of Geunsia are consistently similar with coarsely reticulate exine surface while section Callicarpa had a wide range of variations which might support the concept that Geunsia and Callicarpa as separate genus. The result of exine ornamentation reveals that this character is useful for the infrageneric classification of Callicarpa.

In conclusion, pollen morphology of the genus Callicarpa has shown interesting diagnostic value, thus, allowing evidence to support its relationship with Geunsia. Likewise, pollen morphology does support the supposition of other studies to recognize Geunsia as synonyms of Callicarpa when pollen size and shape class were observed. However, exine ornamentation does provide evidence to differentiate Callicarpa from Geunsia which may result in separation of genera. But authors suggest a better sampling of the section Callicarpa and Geunsia be able to gather more concrete evidence in its phylogenetic relationship.

\section{ACKNOWLEDGEMENTS}

We would like to thank the director and curator of the Singapore herbarium for allowing us to examine and collect specimens of polliniferous material. The first author also would like to thank the Commission on Higher Education (CHEd) for the Scholarship and Dissertation grant. Likewise, we would like to thank the Department of Environment and Natural Resources (DENR), Region 5 for granting us the gratuitous permit which allows us to collect samples of flowers we need. Last but not the least, we would like to express thanks to the Analytical Services Laboratory (ASL) of UST-RCNAS for the usage of SEM.

\section{REFERENCES}

Abu-Asab M, Cantino P. 1993. Phylogenetic implications of pollen morphology in Tribe Ajugeae (Labiatae). Syst Bot 18 (1): 100-122.

Blume CL. 1823. Catalogus van eenige der merkwaardigste zoo in- als uit-heemsche gewassen, te vinden in's lands plantentuin te Buitenzorg, Batavia.

Bramley G. 2009. The genus Callicarpa (Lamiaceae) on Borneo. Botanical J Linn Soc 159 (3): 416-455.

Bramley G. 2013. The genus Callicarpa (Lamiaceae) in the Philippines. Kew Bulletin, 68(3): 369-418.

Briquet J. 1895. Verbenaceae. In: Engler A, Prantl K (eds.) Die naturlichen Pflanzenfamilien, IV, 3a. Wilhelm Engelmann, Leipzig.

Brown, R. 1810. Verbenaceae. "Prodromus Florae Novae Hollandiae et Insulae Van-Diemen": 510-514. Richard Taylor \& Co., London.

Burtt BL. 1969. Sarawak plants. Notes R Bot Gard Edin 29: 149-151.

Cantino PD, Sanders RW. 1986. Subfamilial classification of Labiatae. Syst Bot 11: 163-185.

Cantino PD. 1992. Evidence for a polyphyletic origin of the Labiatae. Ann Missouri Bot Gard 79 (2): 361.

Celenk S, Tarimcilar G, Bicakci A, Kaynak G, Malyer H. 2008. A palynological study of the genus Mentha L. (Lamiaceae). Bot J Linn Soc 157 (1): 141-154.

Chang HT. 1951. A Review of the Chinese species of Callicarpa. Acta Phytotax Sin 1: 269 -312.

Erdtman G. 1952. Pollen Morphology and Plant Taxonomy: Angiosperms. Chronica Botanica Co., Waltham, MA.

Erdtman G. 1971. Pollen Morphology and Plant Taxonomy of Angiosperms. Angiosperms. Hafner Publishing Co, New York.

Fang WZ. 1982. Callicarpa L. (Verbenaceae). In: Pei C, Chen SL (eds.) Flora Reipublicae Popularis Sinicae, Science Press, Beijing.

Gaertner J. 1791. "De Fructibus et Seminibus Plantarum". GH Schramm, Tubingen 2: 80-81.

Govaerts R, Paton AJ, Harvey Y, Navarro T. 2007. World Checklist of Lamiaceae. The Board of Trustees of the Royal Botanic Gardens, Kew. http://www.kew.org/wcsp

Halbritter H. et al. 2018. How to Describe and Illustrate Pollen Grains. In: Illustrated Pollen Terminology. Springer, Cham. DOI: 10.1007/9783-319-71365-6_5

Harley RM, Atkins S, Budantsev AL, et al. 2004. Labiatae. In: Kubitzki K (ed.). The Families and Genera of Vascular Plants, Vol. 4. SpringerVerlag, Berlin.

Hesse M. et al. 2009. Illustrated Pollen Terminology. $2^{\text {nd }}$ ed. Springer International Publishing, New York. DOI: 10.1007/978-3-319-713656

Hou D. 1969. Pollen of Sarawakodendron (Celastraceae) and some related genera, with notes on techniques. Blumea 17: 97-120.

Lam HJ, Bakhuizen van den Brink RC. 1921. Revision of the Verbenaceae of the Dutch East-Indies and surrounding countries. Bulletin du Jardin Botanique Série III 3: 1-116 \& I-III.

Lam HJ. 1919. "The Verbenaceae of the Malayan Archipelago". M. De Waal, Groningen.

Lamarck JBAP de. 1783. Encyclopedie Methodique Botanique. Plomteux, Liege.

Lamarck JBAP de. 1791. "Tableau Encyclopedique et Methodique des Trois Regnes de la Nature. Botanique". Vol. 1. Pancoucke, Paris.

Li B, Olmstead RG. 2017. Two new subfamilies in Lamiaceae. Phytotaxa 313 (2): 222. DOI: $10.11646 /$ phytotaxa.313.2.9

Linnaeus C. 1753. Species plantarum: exhibentes plantas rite cognitas, ad genera relatas, cum differentiis specificis, nominibus trivialibus, synonymis selectis, locis natalibus, secundum systema sexuale digestas. Impensis Laurentii Salvii, Holmiae 1: 560.

Liu, BL. 1985. Pollen morphology of the family Verbenaceae in China. Bull Bot Res 5: 23-62.

Loureiro J. 1793. "Flora Cochinchinensis". Ed. 1, Vol. 1. Laurentius Slavius, Stockholm.

Ma Z, Bramley G, Zhang D. 2015. Pollen morphology of Callicarpa L. (Lamiaceae) from China and its systematic implications. Plant Syst Evol 302 (1): 67-88. 
Moldenke HN. 1982. Additional notes on the genus Geunsia. Phytologia 50: 143-151.

Murray JA. 1774. "Caroli a Linné Systema Vegetabilium Secundum Classes, Ordines, Genera, Species cum Characteribus et Differentiis". J.C. Dietrich, Göttingen.

Nilsson S. 2000. Lolita J. Bulalacao, "Pollen Flora of the Philippines 1" Grana 39 (1): 63-64, DOI: 10.1080/00173130150503821.

Pelser PB, Barcelona JF, Nickrent DL. (eds.). 2011 onwards. Co's Digital Flora of the Philippines. https://www.philippineplants.org/

Perveen A, Qaiser M. 2007. Pollen Flora of Pakistan-LIII. Verbenaceae. Pak J Bot 39 (3): 663-669.

Punt W, Hoen PP, Blackmore S, Nilsson S, Le Thomas A. 2007. Glossary of pollen and spore terminology. Rev Palaeobot Palynol 143: 1-81.

Raeuschel EA. 1797. Nomenclator Botanicus. $3^{\text {rd }}$ ed. J.G. Feind, Leipzig.
Raj B. 1983. A contribution to the pollen morphology of Verbenaceae. Rev Palaeobot Palynol 39 (3-4): 343-422

Schauer JC. 1847. In: de Candolle A (ed.). Prodromus Systematis Naturalis Regni Vegetabilis 11: 522-700.

Sebsebe D, Harley M. 1992. Trichome, seed surface and pollen characters in Stachys (Lamioideae: Labiatae) in tropical Africa. In: Harley RM, Reynolds T (eds.). Advances in Labiatae Science. Royal Botanic Gardens, Kew.

Thorne RF. 1992. Classification and geography of the flowering plants. Bot Rev 58: 225-348.

Van Steenis CGGJ. 1967. Miscellaneous Botanical Notes XVII: A remarkable myrmecophyte, Callicarpasaccatan sp., from Sarawak and some allied species. Blumea 15: 145-155.

Wei ZX. 2003. Pollen flora of seed plants. Yunnan Science and Technology Press, Kunming. 